\title{
Investigation of geometric height effects on the performance of Room Acoustic for Studios
}

\author{
Okafor P.U., and Eneh I.I. \\ Department of Electrical/Electronic Engineering Enugu State University of Science and Technology Nigeria.
}

\begin{abstract}
Audio studios are designed to have necessary acoustic properties that will guarantee dynamic audio quality with precision and accuracy that is void of distortion but, with improved decay rate. Apparently the decay rate of a room is a function of the absorptive materials used in the room design and construction, the geometric measurement, and the frequency of the sound. Two broadcasting studios were investigated to ascertain the acoustic performance at different geometric heights. Issues to be considered are the reverberation time and the height at which decay rates were even.
\end{abstract}

Keywords: - Reverberation time, Decay rate, Acoustic.

\section{INTRODUCTION}

Basically, audio broadcasting is a means by which analogue and digital information signal is being transmitted either wired or wireless from a source through a channel to a receiver at a distance. The output signal is largely dependent on the input signal, apparently if the studio output is distorted, the reception quality will invariably be affected. Perhaps, it is paramount that in design and construction of broadcasting studios, that the design is constrained within the principles of room acoustic.

Considering developing countries, there is need to improve the performance of broadcasting studios since the existing studios were constructed by non professionals without scientific data. The scientific approach to this work will nevertheless stir up a challenge to communication engineers to re-evaluate the communication systems with a view of improving existing ones.

It is therefore imperative to consider acoustic factor in design and construction of a room or other enclosure because, it tends to filter out the external sounds and thereby reducing their masking effect (Onoh, 2005). The output signal must attain a reverberation time of $60 \mathrm{~dB}$ which according to Wallace Sabin's discovery, determined that a good acoustic studio will have a reverberation time of $60 \mathrm{~dB}$ at a given frequency when a sound source is switched off. This paper will use two broadcasting studios in Nigeria to investigate the effects of geometric heights on the performance of room acoustic of studios.

\section{EXPERIMENTAL DESIGN}

Radio Nigeria (RN) and Nigerian Television Authority (NTA) broadcasting studios which are located at Enugu in the eastern part of Nigeria were used. RN and NTA geometric heights of $5 \mathrm{~m}$ and $6.8 \mathrm{~m}$ were used as reference point. These studios are grouped as small room acoustics and as a result, the statistical equations are almost invalid since the use of acoustical absorption materials was prominent in the design and construction. To determine the room acoustic, the reverberation time must be considered. According to (Sabine, 1898) the reverberation equation is the active formula for the calculation of the room acoustics. It states that:

Reverberation time $\left(\mathrm{RT}_{60}\right)=\mathrm{k} \cdot \mathrm{V} / \mathrm{A}$

$\mathrm{K}=(24 \cdot \ln 10) / \mathrm{C}_{20}$

$\mathrm{K}=0.161$

$\mathrm{V}=$ the room volume in $\mathrm{m}^{3}$.

$\mathrm{A}=\alpha . \mathrm{S}$ (equivalent absorption surface area in $\mathrm{m}^{2}$ )

$\alpha=$ absorption coefficient

$s=$ absorption surface area in $\mathrm{m}^{2}$

$\mathrm{A}=\alpha_{1} * s_{1}+\alpha_{2} * s_{2}+\alpha_{\mathrm{n}} * s_{\mathrm{n}}$

$\mathrm{C}_{20}=$ speed of sound is $343 \mathrm{~m} / \mathrm{s} 20^{\circ} \mathrm{C}$.

\subsection{Small room acoustic}

In small room acoustics, the properties of the room are considered instead of the statistical equations because room modes rather than a statistical sound field are prominent. Rooms modes are the collection of resonance that exist in a room when the room is excited by an acoustic source such speaker (Schroeder, 1974).

The acoustical size of a room is the frequency dependent. It has been observed that in small rooms, the low frequencies resonate and this happens when one or more of the dimensions of the room support a particular 
Investigation of geometric height effects on the performance of Room Acoustic for Studios.

frequency. Apparently, a diaphragmatic absorber can be used to dampen the frequency. Therefore Eigen mode which represents standing waves is dependent upon the internal dimensions of an enclosure (Oliver and Cage 1999).

The frequencies of the axial, oblique and tangential modes, can be calculated using

$\mathrm{F}=\frac{c}{2} \sqrt{\left(\frac{n_{x}}{L}\right)^{2}+\left(\frac{n_{y}}{B}\right)^{2}+\left(\frac{n_{z}}{H}\right)^{2}}$

Where;

$\mathrm{F}=$ frequency of the mode in $\mathrm{Hz}$

$\mathrm{C}=$ Speed of the sound $\left(343 \mathrm{~m} / \mathrm{s}\right.$ at $\left.20^{\circ} \mathrm{C}\right)$

$n_{x}=$ order of the mode of the room length

$n_{y}=$ order of the mode of the room width

$n_{z}=$ order of the mode of the room height

L, B, H = Length, Width, Height of the room in metres.

\subsection{Decay rate}

Decay rate $\left(D_{R}\right)$ is the time rate at a stated frequency, at which sound pressure level decreases in a room measured in decibel per second $(\mathrm{db} / \mathrm{s})$.

$\mathrm{D}_{\mathrm{R}}=60 \mathrm{~dB} / \mathrm{RT}_{60}$

Where $\mathrm{RT}_{60}$ is the reverberation time.

\section{PROCESS PARAMETERS}

The studio's design parameters used for the experiment are outlined in tables 1 and 2 below. These initial parameters are used as the reference point.

Table 1: RN Studio Parameters

\begin{tabular}{|c|c|c|c|c|c|c|}
\hline Width $4.9 \mathrm{~m}$ & \multicolumn{2}{|l|}{ Length $5.0 \mathrm{~m}$} & \multicolumn{4}{|c|}{ Height $3.0 \mathrm{~m}$} \\
\hline \multirow[t]{2}{*}{ wall } & \multirow{2}{*}{$\begin{array}{l}\text { Construction } \\
\text { Material }\end{array}$} & \multicolumn{5}{|c|}{ Windows, Doors and Other Surfaces } \\
\hline & & Deflection Material & size & & & Quantity \\
\hline Front & Glass-large pane & Glass-large pane & 1.9 & * & 1.3 & 1 \\
\hline Back & Plywood paneling & Plywood paneling & 0.9 & $*$ & 0.3 & 6 \\
\hline Left & Gypsum board & Gypsum board & 0.5 & * & 0.5 & 21 \\
\hline Right & Gypsum board & Gypsum board & 0.5 & $*$ & 0.5 & 21 \\
\hline Ceiling & Gypsum board & Gypsum board & 0.5 & * & 0.5 & 50 \\
\hline Floor & Carpet on concrete & Carpet on concrete & 1.9 & $*$ & 1,3 & 1 \\
\hline
\end{tabular}

Table 2: NTA Studio Parameters

\begin{tabular}{|l|l|l|l|l|l|l|}
\hline Width 5.2m & Length 5.0m & \multicolumn{4}{l|}{ Height 6.8m } \\
\hline \multirow{2}{*}{ wall } & Construction Material & \multicolumn{4}{|l|}{ Windows, Doors and Other Surfaces } \\
\cline { 3 - 7 } & & Deflection Material & \multicolumn{2}{|l|}{ size } & \multicolumn{2}{l|}{ Quantity } \\
\hline Front & Glass-large pane & Glass-large pane & 2.5 & $*$ & 1.4 & 1 \\
\hline Back & Gypsum board & Gypsum board & 1.5 & $*$ & 1.5 & 23 \\
\hline Left & Gypsum board & Gypsum board & 1.5 & $*$ & 1.5 & 23 \\
\hline Right & Gypsum board & Gypsum board & 1.5 & $*$ & 1.5 & 23 \\
\hline Ceiling & Gypsum board & Gypsum board & 0.5 & $*$ & 0.5 & 144 \\
\hline floor & Drapery-heavy weight & Drapery-heavy weight & 7.0 & $*$ & 6.8 & 1 \\
\hline
\end{tabular}

\section{EXPERIMENTAL RESULT}

The decay time shouldn't be excessively long, and the correct treatment will also help to minimize peaks and troughs in the lower part of the frequency spectrum that are caused by standing waves related to room modes . Reverberation time (RTs) is an indicator of the sound quality within a space for both speech and music. According to soundonsound.com, in the studio area, an optimum reverb time for speech might be somewhere between 0.2 and 0.5 seconds.

It follows that shorter RTs less than $1.0 \mathrm{sec}$ are preferred for good intelligibility in teaching, conference and meeting spaces to ensure optimum speech communication. However for music making and listening in halls and auditoria, longer RTs greater than $1.5 \mathrm{sec}$ are desirable. 
Investigation of geometric height effects on the performance of Room Acoustic for Studios.

\subsection{Height and frequency variation}

Frequency ranges of $125 \mathrm{~Hz}, 250 \mathrm{~Hz}, 500 \mathrm{~Hz}, 1000 \mathrm{~Hz}, 2000 \mathrm{~Hz}$ and $4000 \mathrm{~Hz}$ and geometric parameters: width, length and height were varied and computed in respect to the reverberation time and the output result were tabulated as shown in tables 3 and 4 below. The heights were varied on six different occasions with the initial studio heights $(5 \mathrm{~m}$ and $6.8 \mathrm{~m})$ as reference point.

Table 3: RN Reverberation time at different Heights and Frequencies

\begin{tabular}{|c|c|c|c|c|c|c|}
\hline \multirow[t]{2}{*}{$\overline{\text { Height (m) }}$} & \multicolumn{6}{|c|}{ Frequencies $(\mathrm{Hz})$} \\
\hline & 125 & 250 & 500 & 1000 & 2000 & 4000 \\
\hline 2.0 & $\begin{array}{l}0.47 \\
\end{array}$ & 0.94 & 1.05 & 0.66 & 0.41 & 0.37 \\
\hline 3.0 & 0.56 & 1.12 & 1.32 & 0.92 & 0.58 & 0.52 \\
\hline 4.0 & 0.61 & 1.23 & 1.52 & 1.14 & 0.72 & 0.65 \\
\hline 5.0 & 0.65 & 1.31 & $\begin{array}{l}1.67 \\
\end{array}$ & 1.34 & 0.85 & 0.76 \\
\hline 6.0 & 0.68 & 1.37 & $\begin{array}{l}1.79 \\
\end{array}$ & 1.51 & 0.97 & 0.87 \\
\hline 7.0 & 0.7 & 1.42 & 1.88 & 1.66 & 1.07 & 0.96 \\
\hline 8.0 & 0.72 & 1.45 & 1.96 & 1.8 & 1.16 & 1.04 \\
\hline
\end{tabular}

Table 4: NTA Reverberation time at different Heights and frequencies

\begin{tabular}{|c|c|c|c|c|c|c|}
\hline \multirow[t]{2}{*}{ Height (m) } & \multicolumn{6}{|c|}{ Frequencies $(\mathrm{Hz})$} \\
\hline & 125 & 250 & 500 & 1000 & 2000 & 4000 \\
\hline 5.0 & 0.71 & 1.16 & 1.11 & 0.93 & 0.85 & 0.84 \\
\hline 6.8 & 0.79 & 1.4 & 1.42 & 1.22 & 1.09 & 1.06 \\
\hline 7.0 & 0.8 & 1.42 & 1.45 & 1.25 & 1.11 & 1.08 \\
\hline 8.0 & 0.83 & 1.53 & 1.61 & 1.4 & 1.23 & 1.18 \\
\hline 9.0 & 0.86 & 1.62 & 1.76 & 1.54 & 1.33 & 1.28 \\
\hline 10 & 0.88 & 1.71 & 1,89 & 1.67 & 1.44 & 1.37 \\
\hline 11 & 0.9 & 1.79 & 2.02 & 1.8 & 1.53 & 1.45 \\
\hline
\end{tabular}

Since the decay rate of a room is a function of the absorptive materials used in the room construction, the geometric measurement and the frequency of the sound, it is therefore very necessary to collate, compute and analyzed these data to determine the decay rate. The decay rate of RN and NTA were calculated and tabulated as shown on tables 5 and 6 below.

Table 5: RN frequency, Reverberation time and Decay Rate

\begin{tabular}{|l|l|l|l|}
\hline Height (meter) & Frequency $(\mathbf{H z})$ & Time $($ seconds) & Decay Rate $\mathbf{( d B} / \mathbf{s})$ \\
\hline $\mathbf{2 . 0}$ & 125 & 0.47 & 136.36 \\
\hline & 250 & 0.94 & 63.83 \\
\hline & 500 & 1.05 & 57.14 \\
\hline & 1000 & 0.66 & 90.91 \\
\hline & 2000 & 0.41 & 146.34 \\
\hline & 4000 & 0.37 & 162.16 \\
\hline & & & \\
\hline $\mathbf{3 . 0}$ & 125 & 0.56 & 107.14 \\
\hline & 250 & 1.12 & 53.57 \\
\hline & 500 & 1.32 & 45.45 \\
\hline & 1000 & 0.92 & 65.22 \\
\hline & 2000 & 0.58 & 103.45 \\
\hline & 4000 & 0.52 & 115.38 \\
\hline & & & 83.33 \\
\hline $\mathbf{8 . 0}$ & 125 & 0.72 & 41.38 \\
\hline & 250 & 1.45 & 30.61 \\
\hline & 500 & 1.96 & 33.33 \\
\hline & 1000 & 1.8 & 51.72 \\
\hline & 2000 & 1.16 & 57.69 \\
\hline & 4000 & 1.04 &
\end{tabular}


Investigation of geometric height effects on the performance of Room Acoustic for Studios.

Table 6: NTA frequency, Reverberation time and Decay Rate

\begin{tabular}{|c|c|c|c|}
\hline Height (meter) & Frequency $(\mathrm{Hz})$ & Time (seconds) & Decay Rate $(\mathrm{dB} / \mathrm{s})$ \\
\hline \multirow[t]{6}{*}{5.0} & 125 & 0.71 & 84.51 \\
\hline & 250 & 1.16 & 51.72 \\
\hline & 500 & 1.11 & 54.05 \\
\hline & 1000 & 0.93 & 64.52 \\
\hline & 2000 & 0.85 & 70.59 \\
\hline & 4000 & 0.84 & 71.43 \\
\hline \multirow[t]{6}{*}{6.8} & 125 & 0.79 & 75.95 \\
\hline & 250 & 1.4 & 42.86 \\
\hline & 500 & 1.42 & 42.25 \\
\hline & 1000 & 1.22 & 49.18 \\
\hline & 2000 & 1.09 & 55.05 \\
\hline & 4000 & 1.06 & 66.6 \\
\hline \multirow[t]{6}{*}{10} & 125 & 0.88 & 68.18 \\
\hline & 250 & 1.71 & 35.09 \\
\hline & 500 & 1.89 & 31.75 \\
\hline & 1000 & 1.67 & 35.93 \\
\hline & 2000 & 1.44 & 41.67 \\
\hline & 4000 & 1.37 & 43.8 \\
\hline
\end{tabular}

\subsection{Geometric Height against Reverberation time}

The result of reverberation time achieved at various heights were tabulated in figures 1 and 2 below, it can be seen from the result that the reverberation time of 0.2 to 0.5 were virtually achieved. It is observed that the most suitable reverb time at which the decay rate were most even lies between 0.92 and 1.65 respectively, considering the increment in the height. It was also observed that varying other studio's geometric parameters such as width and length has little effect compared to the effect of increasing the height.

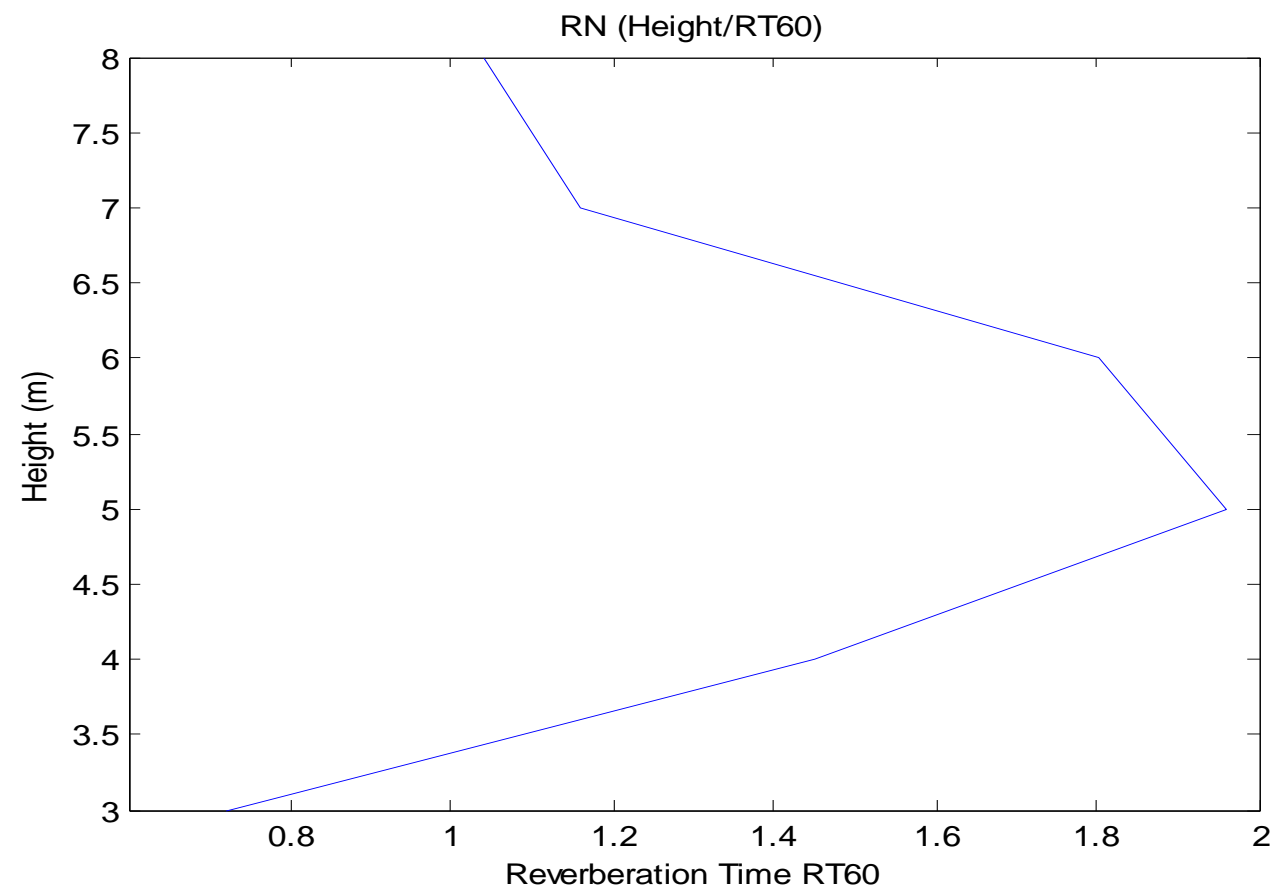

Figure 1: Reverberation time of studio (RN) 


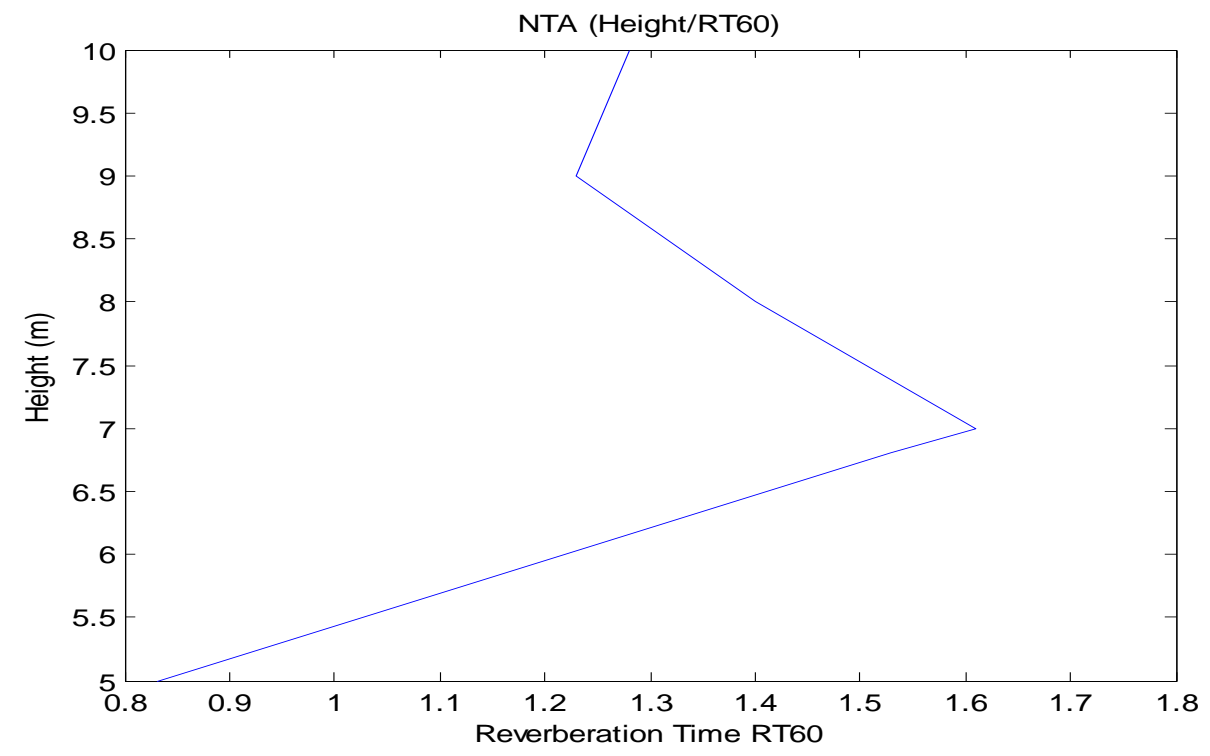

Figure 2: Reverberation time of studio (NTA)

\subsection{Decay rate against the Frequencies}

The acoustic requirement of control room and live space are quite different because of their usage purposes. Always, the aim of employing acoustic treatment in design and construction of control room and live space is to achieve the most even decay rate across all frequencies. From the experimental result as shown in figure 3 below, shows that at the $3 \mathrm{~m}$ height parameter (which is the reference point), that the decay rate achieved across the frequencies were not as even as compared to those achieved at $7 \mathrm{~m}$ and $8 \mathrm{~m}$ respectively.

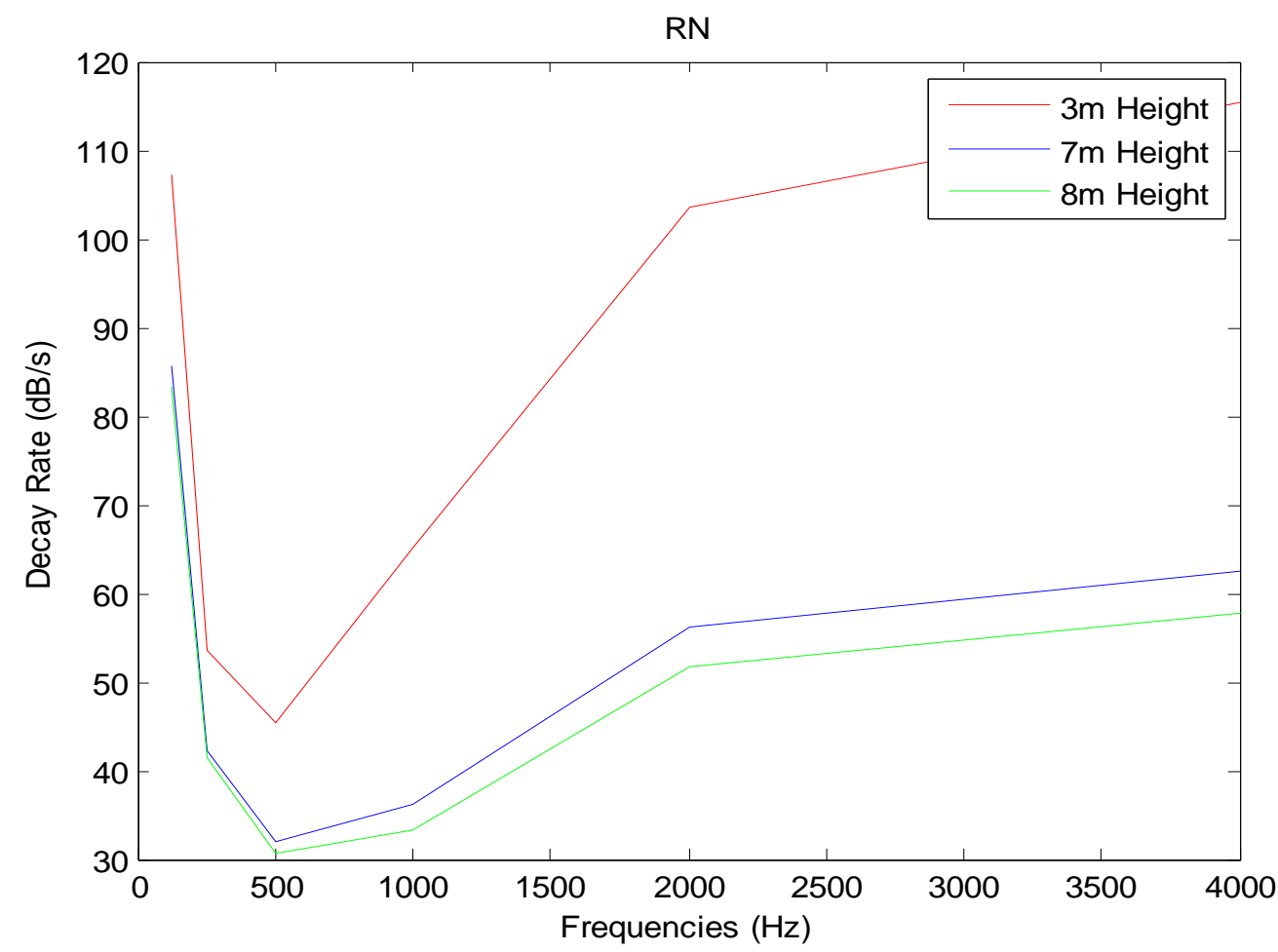

Figure 3: Decay rate at various studio heights $(\mathrm{RN})$

It is observed in figure 4 below, that the most even decay rate across the frequencies were achieved at $7 \mathrm{~m}$ and $8 \mathrm{~m}$ heights respectively. Again, this signifies that as the studio's height is been increased, the decay rate tends to attain an even state. It is observed also that the studio decay rate starts achieving even state as the frequencies tends to $2000 \mathrm{~Hz}$ and above. 


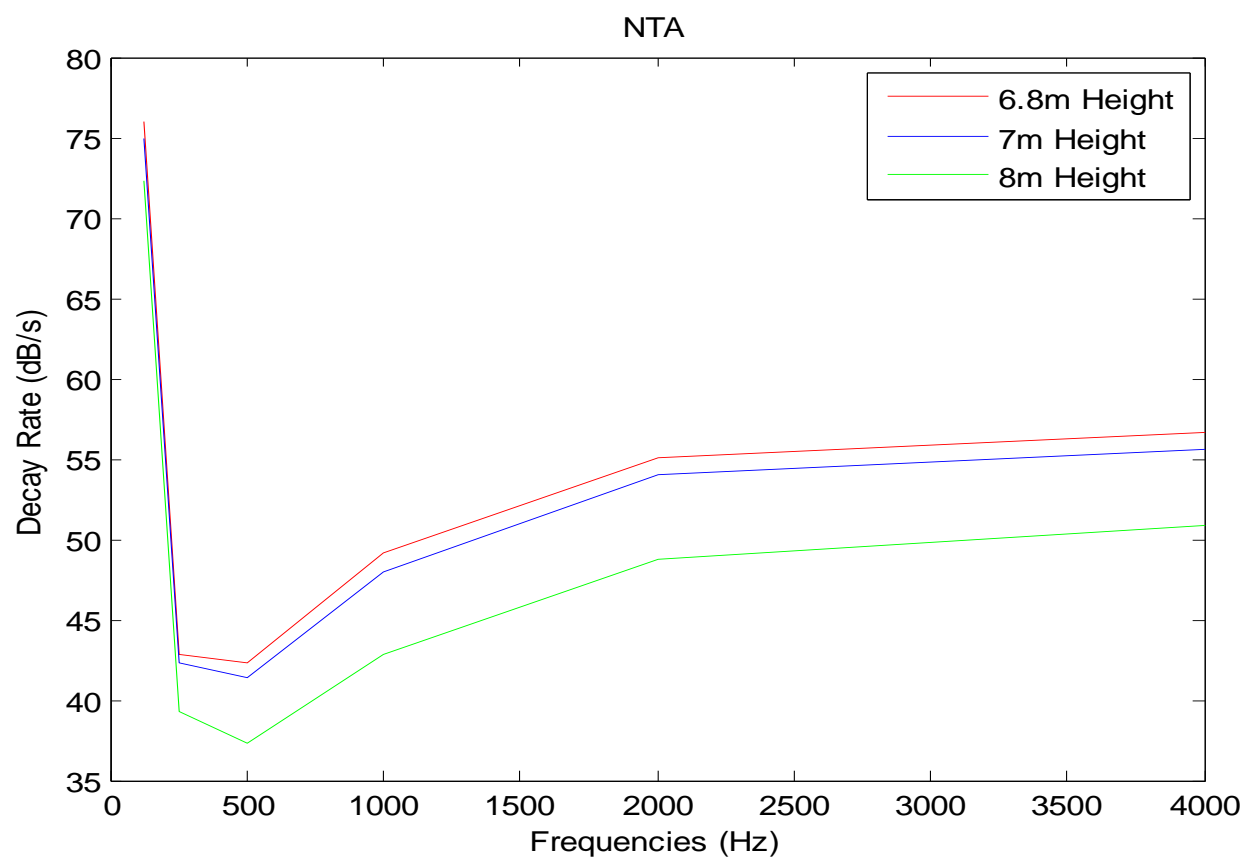

Figure 4: Decay rate at various studio heights

\section{CONCLUSION}

Irrespective of the fact that the studios were designed and constructed with absorbent materials to damp the sound waves, the most even decay rate across the frequencies were virtually achieved at reference geometric heights of $3 \mathrm{~m}$ and $6.8 \mathrm{~m}$ respectively. From the experimental result, it is obvious that the decay rates were most even across the frequencies as the geometric heights were incremented within the heights ranges of $7 \mathrm{~m}$ and $8 \mathrm{~m}$. This paper suggest that the communication engineers will re-evaluate the communication systems as regards to the existing studios and recommends designing and construction of new studios with proper absorbent materials and geometric parameters of height between $7 \mathrm{~m}$ and $8 \mathrm{~m}$ for small room acoustic, as to improve the reverberation time with a decay rate of or close to $60 \mathrm{~dB}$.

\section{REFERENCES}

[1] Joyce, W.B. (1985): "Power series for the reverberation time". Pp.5 - 6

[2] Waterhouse, R.Y. (2001): "Theory of howlback in reverberating rooms". Pp. 65 - 58

[3] Davis, Don and Patronic, Eugene Jr.(1984): "Sound System Engineering" Third Edition. Pp. 81 - 83

[4] Snow, W.B. (2001): "Application of acoustical Engineering Principles to home music rooms". Pp. 23 28

[5] Onoh, Greg N. (2008): "Principles of Telecommunications". Pp.33 - 37

[6] Harvey, Fletcher. (2002): "Speech and hearing in Communication". Pp 17 - 20

[7] Klein, W. (1996): “ Articulation loss in consonants as a basis for design and judgment of sound reinforcement systems". Pp. 2629.

[8] Oliver, B.M. and Cage, J.M. (1999): “Electronics measurements and instrumentation". Pp. 10 - 14

[9] Shankland, R.S. (2001): “Acoustics of Greek theaters". Pp. 45 - 52.

[10] Haas, H. (1972): "The effect of a single echo on the Audibility of speech". Pp. 16 - 17

[11] Shroeder, M.R. (1974): "Computers in acoustics: Symbiosis of an old science and a new tool". Pp. 32 38.

[12] Soundonsound.com, Practical Acoustic Treament, Part 3. Online, available at http://www.soundonsound.com/sos/sep98/articles/acoustic_3.html. Accessed on $8^{\text {th }}$ October, 2013.

[13] Morse, P.M. (1998): "Vibration and Sound". Pp. 63 - 64.

[14] Sabine, W.C.(1922): “Collected papers on acoustics". Pp. 87 -95

[15] Peutz M.A (2988): "Speech reception and information”. Pp. 41 - 42

[16] Matlab Projects, Echo and Reverberation. Online, available at http://matlabsproj.blogspot.com/2012/06/echo-and-reverberation.html. Accessed 0n $7^{\text {th }}$ October, 2013.

[17] H. ARAU-PUCHADES, An Improved Reverberation Formula, Acoustica. 65, 163 - 180 (1988)

[18] C. F. EYRING, Reverberation Time in "Dead" Rooms, J. Acoust. Soc. Amer., !,217 - 241 (1930) 